\title{
MicroRNA-9 suppresses human prostate cancer cell viability, invasion and migration via modulation of mitogen-activated protein kinase kinase kinase 3 expression
}

\author{
ZUNMENG SANG, XUEWEN JIANG, LONGFEI GUO and GANG YIN \\ Department of Urology, Qilu Hospital of Shandong University, Jinan, Shandong 250012, P.R. China
}

Received March 21, 2018; Accepted September 28, 2018

DOI: $10.3892 / \mathrm{mmr} .2019 .10065$

\begin{abstract}
MicroRNAs (miRs) are small non-coding RNA molecules that regulate gene expression at the post-transcriptional level. Aberrant expression of miR-9 has been reported to be involved in the tumorigenesis and progression of various malignancies. However, its role in prostate cancer (PC) has not been completely clarified. In the present study, miR-9 expression was examined in different PC cell lines, patient tissues and a mouse model. Cell Counting Kit- 8 and BrdU immunofluorescence assays were performed to assess the effect of miR-9 on the viability of PC cells, while Transwell and wound-healing assays were utilized to evaluate the migration and invasion of PC cells expressing miR-9. Furthermore, a dual-luciferase reporter assay was performed to verify whether mitogen-activated protein kinase kinase kinase 3 (MEKK3) was a direct target of miR-9. The results demonstrated significant downregulation of miR-9 expression in different PC cell lines and 31 human PC tissues, as compared with that in a normal prostate cell line and adjacent normal tissues, respectively. By contrast, upregulation of MEKK3 was confirmed in human PC tissue samples, with its level inversely associated with miR-9 expression. Overexpression of miR-9 in six different PC cell lines (DU145, LNCaP, 22Rv1, PC-3, C4-2B and VCaP) reduced the cell viability and migration. Furthermore, it was demonstrated that the 3'-untranslated region of MEKK3 was a target of miR-9, and that MEKK3 overexpression prevented the inhibitory effects of miR-9 on the viability, migration and invasion of PC cells. miR-9 overexpressing tumor cells also exhibited growth delay in comparison with control tumor cells in vivo. Taken together, the current study findings provided novel insights into the underlying molecular mechanisms of PC oncogenesis, which may support the development of new therapeutic approaches for the treatment of PC.
\end{abstract}

Correspondence to: Dr Gang Yin, Department of Urology, Qilu Hospital of Shandong University, 107 Wenhuaxilu Road, Jinan, Shandong 250012, P.R. China

E-mail: yingang54321@163.com;.yg_2000@sina.com

Key words: prostate cancer, viability, microRNA-9, mitogen-activated protein kinase kinase kinase 3

\section{Introduction}

Prostate cancer (PC) is among the top 10 cancer types worldwide in terms of its high rates of prevalence and mortality. Recent research has indicated that the estimated mortalities associated with PC are higher in comparison with any other cancer type, excluding lung carcinoma (1). PC is typically treated with a combination of prostatectomy, radiation, chemotherapeutics and androgen ablation (2). However, the occurrence of distant invasion and migration of PC result in poor prognosis (3). At present, there is increasing research regarding PC invasion and migration, which are the major malignant properties of $\mathrm{PC}$ and main causes of mortality in patients (4-6).

MicroRNAs (miRs) are a class of small non-coding RNAs (7). The update of the miRBase in 2011, a biological database of miR sequences, currently includes $>30,000$ known mature miR sequences described in 9 species (8). It is well established that ectopic miR expression is strongly associated with tumorigenesis. miRs may be oncogenic or tumor suppressors, and have been widely reported as potential targets for cancer molecular therapies (9). Furthermore, miRs may be used as biomarkers or therapeutic targets for the diagnosis and prognosis of multiple types of cancer. Studies on PC invasion and metastasis have revealed a pivotal role of miRs during these processes, as miRs post-transcriptionally regulate a variety of invasion or metastasis-associated oncogenes $(10,11)$.

The functional implication of miR-9 in evolution is demonstrated by its conservation at the nucleotide level in several different species, and it is known that the mature miR-9 sequence is identical in insects and humans (12). miR-9 has been extensively investigated in various biological processes, including neural progenitor cell proliferation and migration (13), neuronal differentiation (14), apoptotic cell death (15), brain function, neurodegeneration (16) and cancer (17). Aberrant miR-9 expression occurs in several types of cancer, suggesting that miR-9 is involved in tumorigenesis and cancer progression. However, through regulation of various mRNA targets, miR-9 may have divergent effects on the proliferation of various cancer cells (18-21). Although numerous functions of miR-9 have been reported, the mechanisms underlying its oncogenic or tumor suppressor functions have yet to be fully revealed. 
As a major signaling pathway participating in signal transduction from the plasma to the nucleus, mitogen-activated protein kinases (MAPKs) respond to cellular stressors and various growth factors to mediate signaling (22). Mitogen-activated protein kinase kinase kinase 3 (MEKK3), also known as MAP3K3, belongs to the MAPK family. MEKK3 is a kinase that phosphorylates the serine or threonine of c-Jun N-terminal kinase (JNK), p38 and extracellular signal-regulated kinase (ERK). MEKK3 is an upstream mediator of MAPK pathways regulating cell proliferation, tumorigenesis, apoptosis and inflammatory responses (23). Recently, the ability of MEKK3 to promote the transformation of breast epithelial cells has been revealed, suggesting that it functions as an oncogene (24). However, while MEKK3 is essential for endothelial function, it is not critical for tumorigenesis and angiogenesis (25). Currently, the role of MEKK3 in PC development and its underlying molecular mechanism in tumorigenesis remain unclear.

The aim of the present study was to investigate the effect of miR-9 on PC development. It was demonstrated that alteration of miR-9 expression in different PC cells influenced their proliferation and migration in vitro and in vivo. In addition, alterations in E-cadherin, $\mathrm{N}$-cadherin and Vimentin expression levels were detected at the protein and mRNA level, confirming the effect of miR-9 on the epithelial-mesenchymal transition (EMT) of PC cells. It was also confirmed that miR-9 influenced PC cell behavior via targeting of the MEKK3 3'-untranslated region (3'-UTR). The present study expanded the current understanding on the role of miR-9 as a PC suppressor, and may facilitate the future development of miR-targeted cancer diagnostics and therapeutics.

\section{Materials and methods}

Cell lines and cell culture. Several cell lines were purchased from the Cell Bank of the Chinese Academy of Sciences (Shanghai, China). These included human normal prostate RWPE-1 cells, as well as DU145, LNCaP and PC-3 cells, which are standard PC cell lines used in therapeutic research (26). 22Rv1 was also obtained, which is a human prostate carcinoma epithelial cell line derived from a xenograft that was serially propagated in mice following castration-induced regression and relapse of the parental, androgen-dependent CWR22 xenograft (27). C4-2B cells, a subtype of the LNCaP cell line, and $\mathrm{VCaP}$ cells, an adherent epithelial cell line with high androgen receptor and prostate-specific antigen expression, were also obtained $(28,29)$. VCaP cell line is the only PC cell model that expresses the androgen receptor splice variant, AR-V7, with TMPRSS2-ERG gene fusion.

RWPE-1 cells were cultured in $1 \mathrm{X}$ defined keratinocyte serum-free medium (Invitrogen; Thermo Fisher Scientific, Inc., Waltham, MA, USA). LNCaP, 22Rv1, C4-2B and PC-3 cells were grown in RPMI-1640 medium (Invitrogen; Thermo Fisher Scientific, Inc.) supplemented with $10 \%$ fetal bovine serum (FBS; Invitrogen; Thermo Fisher Scientific, Inc.), while DU145 and VCaP cells were grown in Dulbecco's modified Eagle's medium (Invitrogen; Thermo Fisher Scientific, Inc.) supplemented with $10 \%$ FBS. All cells were incubated at $37^{\circ} \mathrm{C}$ in a humidified atmosphere with $5 \% \mathrm{CO}_{2}$ and routinely subcultured using $0.25 \%(\mathrm{w} / \mathrm{v})$ trypsin-ethylenediaminetetraacetic acid solution.
Patients. PC patients (diagnosed with National Institute for Health and Clinical Excellence (NICE) criteria, n=31) (30) aged between 26 and 70 years, with a mean age of 53 years, were recruited into the present study. Clinicopathological information for these patients was obtained from medical records. The corresponding PC paraneoplastic tissues and their normal adjacent tissues were acquired at $\geq 1 \mathrm{~cm}$ from the neoplastic tissue. All cases were initially treated by prostatectomy and randomly selected at Qilu Hospital of Shandong University (Jinan, China) between March 2011 and April 2016. Specimens were obtained in agreement with the Declaration of Helsinki and were preserved at Qilu Hospital. The experimental protocol was approved by the Ethical Committee of Qilu Hospital of Shandong University (Jinan, China). Written informed consent for sample use in this research was obtained from both patients and clinicians. All samples were reviewed and diagnosed by two independent pathologists.

miR-9 expression vector construction. A versatile expression vector of miR-9 was generated by constructing the human miR-9 precursor region into minicircle vectors. A transthyretin (TTR) gene promoter was inserted upstream of the miR-9 precursor to guarantee liver-specific expression of miR-9 (31). This construct was referred to as TTR-miR-9. To exclude non-specific effects of the plasmid, a miR-9 mismatched expression vector was generated by mutating the seed region of miR-9, termed transthyretin-miR-9-mut.

miR-9 mimic preparation and transfection. $\mathrm{miR}-9 \mathrm{mimic}$ and its scramble control [negative control (NC) mimic] were purchased from GenScript (Piscataway, NJ, USA). miR-9 mimic is an artificial chemically-modified double-strand miRNA, which mimics mature endogenous miR-9 expression subsequent to transfection into cells. Transfection of miRNA mimic was carried out by using Lipofectamine 2000 (Invitrogen; Thermo Fisher Scientific, Inc.) according to the manufacture's protocol. All miRNA treatments proceeded for $48 \mathrm{~h}$. Both miR-9 mimic and miR-NC mimic were formulated in $0.9 \% \mathrm{NaCl}$ to a final concentration of $10 \mathrm{mg} / \mathrm{ml}$.

For enforced expression of MEKK3 in PC cells, open reading frame region of MEKK3 gene was amplified and inserted into the pcDNA3.1 eukaryotic expression vector (Invitrogen; Thermo Fisher Scientific, Inc.). Vector empty pcDNA3.1 was served as negative control (NC). Before transfection, cells were seeded into 6-well plates overnight. $3 \mu \mathrm{g} / \mathrm{ml}$ pcDNA3.1-MEKK3 or pcDNA3.1 plasmid was then transfected into the PC cells by using Lipofectamine 2000 (Invitrogen; Thermo Fisher Scientific, Inc.) according to the manufacturer's protocol.

In vivo tumorigenesis in a PC mouse model. To detect whether upregulation of miR-9 reduced the tumorigenic capacity of PC cells, an intratibial injection model was established. A total of 6 male severe combined immunodeficiency mice at 3-4 weeks old were purchased from Vital River Laboratory Animal Technology Co., Ltd. (Beijing, China). Mice were kept at $23^{\circ} \mathrm{C}$ in a humidified atmosphere (55-65\% humidity) with food and water ad libitum with a 12-h light/dark cycle. In order to establish the PC animal model, each mouse was injected with $1 \times 10^{5}$ stably selected PC-3 cells into its right tibia, while 
with PC-3 cells transfected with NC vector cells were injected into the left tibia, serving as the NC group. Tumor length and width were measured every 3 days after injection, and tumor volume was calculated as follows: Length $\mathrm{x}$ (width $\left.{ }^{2} / 2\right)$. Mice were sacrificed at 33 days after the injection, and the tumors were weighed. Ethical approval of the animal experiments was provided by the Institutional Animal Care and Use Committee of Shandong University Cancer Center (Jinan, China; approval no. L102012016110D).

Cell Counting Kit-8 (CCK-8) assay. PC cell viability was determined by a CCK-8/WST-8 assay (Dojindo Molecular Technologies, Inc., Shanghai, China), which was performed following a standard procedure in a 96 -well plate, according to the manufacturer's protocol. Briefly, cells $\left(5 \times 10^{3}\right.$ cells/well) were seeded in a 96-well plate and grown to $80 \%$ confluence. miR-9 mimic or mimic NC was subsequently transfected into PC cells. At 0, 24, 48 and $72 \mathrm{~h}$ post-transfection, $10 \mu \mathrm{l}$ of CCK-8 reagent was added into each well. After $1 \mathrm{~h}$ of incubation, cell viability was determined by measuring the absorbance of the converted dye at $450 \mathrm{~nm}$.

BrdU immunofluorescence assay. DU145, LNCaP, 22Rv1, PC-3, C4-2B and VCaP cells $\left(1 \sim 5 \times 10^{5}\right)$ were seeded on glass coverslips placed in a 6 -well plate. Following transfection with miR-9 mimic and miR-NC for $48 \mathrm{~h}, 10 \mathrm{mg} / \mathrm{ml} \mathrm{BrdU}$ stock solution in phosphate buffered saline (PBS) was diluted to $1,000 \mathrm{X}$ in the culture medium and incubated for $60 \mathrm{~min}$. Cells were washed with PBS, fixed for $20 \mathrm{~min}$ at $25^{\circ} \mathrm{C}$ in $4 \%$ paraformaldehyde and permeabilized with $0.3 \%$ Triton $\mathrm{X}-100$ for $10 \mathrm{~min}$. Subsequent to blocking with $10 \% \mathrm{FBS}$ for $1 \mathrm{~h}$, cells were incubated with a primary rabbit antibody against BrdU (1:200; cat. no. ab6326, Abcam, Cambridge, UK) overnight at $4^{\circ} \mathrm{C}$ and then incubated with the corresponding secondary antibody coupled to a fluorescent marker, Cy3 (A10520, Thermo Fisher Scientific, Inc.), at room temperature for $2 \mathrm{~h}$. Following DAPI staining for $15 \mathrm{~min}$ at $37^{\circ} \mathrm{C}$ and a further wash with $\mathrm{PBS}$, the cover slips were mounted onto glass slides and visualized using a fluorescence microscope (Olympus 600 auto-biochemical analyzer; Olympus Corporation, Tokyo, Japan) with Image-Pro Plus software (Media Cybernetics, Inc., Rockville, MD, USA) for image analysis. A total of 10 microscopic fields were analyzed to calculate the degree of BrdU staining.

Transwell assays. After $24 \mathrm{~h}$ of transfection, DU145, LNCaP, 22Rv1, PC-3, C4-2B and VCaP cells were harvested by trypsinization and washed once with D-Hank's solution. In order to measure cell invasion, $8-\mu \mathrm{m}$ pore size culture inserts or Matrigel-coated inserts, respectively, were placed into the wells of 24-well plates. In total, $1 \times 10^{5}$ cells were added to the upper chamber, while $400 \mu \mathrm{l} \mathrm{F12} \mathrm{medium} \mathrm{containing} 10 \%$ FBS and $20 \mathrm{ng} / \mathrm{ml}$ Hepatocyte growth factor (HGF) was added to the lower chamber. After $20 \mathrm{~h}$ of incubation, the cells that migrated through the pores were stained with crystal violet and observed under a microscope (Zeiss AG, Oberkochen, Germany).

Wound-healing assay. At $48 \mathrm{~h}$ post-transfection, $1.5 \mathrm{ml}$ of DU145, LNCaP and PC-3 cells $\left(1 \times 10^{5}\right.$ cells $\left./ \mathrm{ml}\right)$ were grown to $100 \%$ confluence in 12 -wells plate. A scratch wound was then generated by scraping the monolayer of the cells with a sterile pipette tip. Next, samples were washed with PBS twice to remove the detached cells, and subsequently incubated for 0 and $48 \mathrm{~h}$ prior to examining and capturing images with an inverted microscope (Nikon Corporation, Tokyo, Japan).

Bioinformatics analysis. The potential targets of miR-9 were predicted using the miRDB database (http://www. mirdb. org). The putative genes that were predicted by algorithms were accepted, and the candidates were selected based on the gene function. MEKK3 was further chose as a target is due to MEKK3 has been widely reported as an oncogene $(32,33)$.

Western blot analysis. Cells were lysed in radioimmunoprecipitation assay buffer (containing $50 \mathrm{mM}$ Tris- $\mathrm{HCl}, 150 \mathrm{mM}$ $\mathrm{NaCl}, 1 \% \mathrm{NP}-40$ and $0.1 \%$ SDS, pH 8.0) supplemented with a protease inhibitor cocktail. The protein concentration was measured using a BCA Protein Quantitation kit. Protein samples were then separated by $10 \%$ SDS-PAGE and electroblotted onto $0.45-\mu \mathrm{m}$ Immobilon polyvinylidene difluoride membranes. The membranes were then blocked with $5 \%$ bovine serum albumin in PBS/Tween-20 for $1 \mathrm{~h}$ at room temperature and incubated overnight at $4^{\circ} \mathrm{C}$ with the following antibodies: Rabbit anti-B-cell lymphoma 2 (Bcl-2; 1:2,000, cat. no. ab59348, Abcam), rabbit anti-Bcl-2-associated X protein (Bax; 1:1,000, cat. no. ab59348, Abcam) and mouse anti-GAPDH (1:5,000, cat. no. ab8245, Abcam) antibodies. Subsequently, membranes were incubated for $1 \mathrm{~h}$ at room temperature with the following Amersham ECL horseradish peroxidase-linked secondary antibodies: Goat anti-mouse IgG $(1: 10,000)$ or goat anti-rabbit IgG $(1: 10,000$; both from GE Healthcare Life Sciences, Little Chalfont, UK). Western blot immunoreactivity was detected using a SuperSignal West Femto Maximum Sensitivity Substrate kit (Thermo Fisher Scientific, Inc.) with a Chemiluminescent detection method of C-DiGit blot scanner (LI-COR Biosciences, Lincoln, NE, USA).

$R N A$ extraction and reverse transcription-quantitative polymerase chain reaction $(R T-q P C R)$. Total RNA was extracted from PC cells following different treatments or from homogenized PC tissues (stored at $-80^{\circ} \mathrm{C}$ ) using TRIzol ${ }^{\circledR}$ reagent (Thermo Fisher Scientific, Inc.), according to manufacturer's protocol. The RNA (10 mg) was reverse transcribed into first-strand complementary DNA (cDNA) using M-MLV reverse transcriptase (Promega Corporation, Madison, WI, USA) for mRNA expression analysis. The levels of miR-9 were determined by SYBR Green incorporation in a Roche Light-Cycler 480 Real-time PCR system (Roche Diagnostics GmbH, Mannheim, Germany). GAPDH and U6 served as an internal control to determine the miR-9, E-cadherin, N-cadherin, Vimentin and MEKK3 expression. The primer sequences used in qPCR were as follows: miR-9, 5'-TGAGGTAGTAAGTTGTATTGTT-3' (forward) and 5'-ACACACTTCCTTACATTCCATT-3' (reverse); E-cadherin, 5'-GGGTTGTCTCAGCCAATGTT-3' (forward) and 5'-CAC CAACACACCCAGCATAG-3' (reverse); N-cadherin, 5'-CGA GCCGCCTGCGCTGCCAC-3' (forward) and 5'-CGCTGC TCTCCGCTCCCCGC-3' (reverse); Vimentin, 5'-AGATCG ATGTGGACGTTTCC-3' (forward) and 5'-CACCTGTCTCCG 

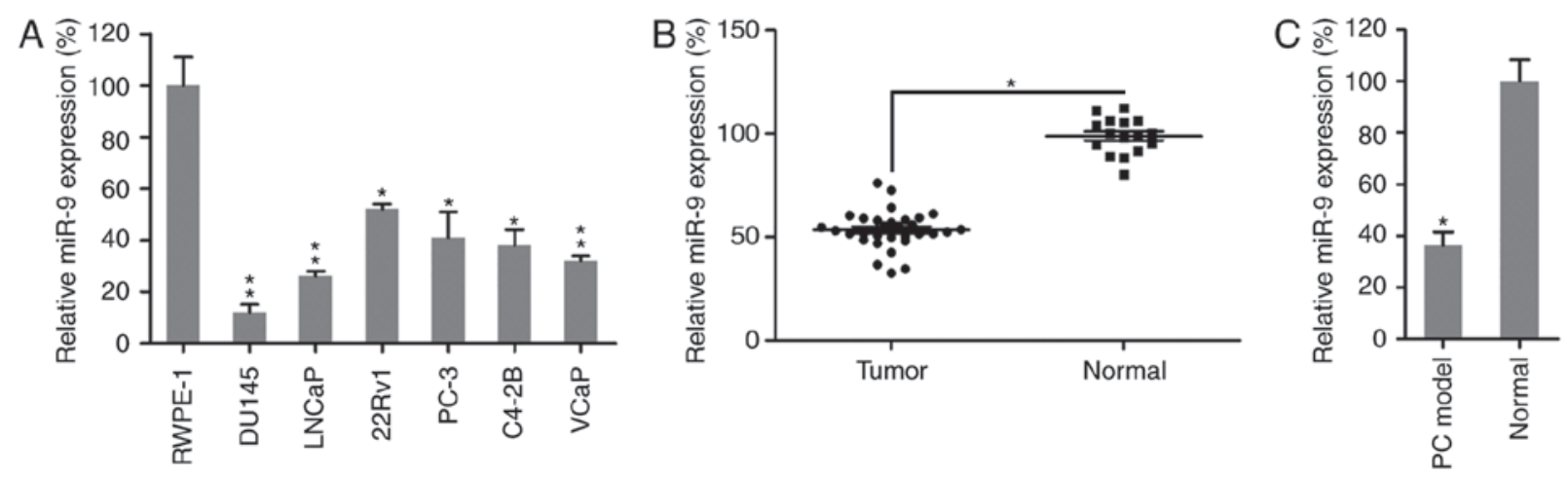

Figure 1. miR-9 expression levels in PC cells, human prostate tissues and mouse tissues. (A) Decreased expression of miR-9 in human PC cell lines was observed compared with that in normal human hepatocytes (RWPE-1 cells). (B) Reduced expression level of miR-9 in human prostate tumors (n=31) versus normal liver tissue ( $\mathrm{n}=16)$. (C) Level of miR-9 in the prostate of PC mice was reduced, compared with that in prostate tissues of normal healthy mice. Data represent the mean \pm standard deviation. ${ }^{*} \mathrm{P}<0.05$ and ${ }^{* * *} \mathrm{P}<0.01$, vs. normal cells or tissues. miR, microRNA; PC, prostate cancer.

GTATTCGT-3' (reverse); MEKK3, 5'-AAGGGGTCAAAG GTGGAACC-3' (forward) and 5'-TGCCTTGATGACGCCGTA TT-3' (reverse); GAPDH, 5'-GGAAAGCTGTGGCGTGAT-3' (forward), 5'-AAGGTGGAAGAATGGGAGTT-3' (reverse). U6, 5'-CTCGCTTCGGCAGCAC (forward)-3' and 5'-ACGCTT CACGAATTTGC-3' (reverse). qPCR was performed in a total volume of $20 \mu$ with SYBR Green PCR Master Mix (4309155, Thermo Fisher Scientific, Inc.) at $95^{\circ} \mathrm{C}$ for $10 \mathrm{~min}$, followed by 40 cycles at $95^{\circ} \mathrm{C}$ for $15 \mathrm{sec}, 60^{\circ} \mathrm{C}$ for $30 \mathrm{sec}$ and $72^{\circ} \mathrm{C}$ for $30 \mathrm{sec}$. The target expression, calculated using the $2^{-\Delta \Delta \mathrm{Cq}} \operatorname{method}(34)$, was obtained by normalizing to the endogenous reference and relative to a calibrator (Mean of the control samples).

Dual-luciferase reporter assay. The MEKK 3 gene was predicted to be a target of miR-9, and their interaction was further examined by dual-luciferase reporter assay. The entire MEKK3 gene 3'-UTR was amplified, constructed and inserted downstream of the GV126 Luciferase gene. Based on the predicted target binding site of miR-9 and the MEKK3 gene, site-directed mutagenesis was employed to abolish the binding site, and the obtained mutant sequence was used as a control. A Renilla luciferase-containing plasmid with a thymidine kinase promoter (pRL-TK vector; Takara Bio, Inc., Otsu, Japan) was used as a reporter control to adjust for transfection efficiency. miR-9 mimic and miR-NC were respectively co-transfected with the luciferase reporter vector into DU145, LNCaP, 22Rv1, PC-3, C4-2B and VCaP cells. Luciferase assay was conducted according to the Dual-Luciferase Assay kit protocol (Promega Corporation, Madison, WI, USA). Briefly, 100 units of myllicin (T10326, Transgenes, Beijing, China) was added to the cells, and then cells were cultured in RPMI-1640/DMEM supplemented with $10 \% \mathrm{FBS}$ in an incubator with $5 \% \mathrm{CO}_{2}$ at $37^{\circ} \mathrm{C}$. The media were replaced every 2 days, and cells were digested with $0.25 \%$ tryptase and subcultured when $70-80 \%$ confluence had been reached in the culture. After overnight culture, culture medium was removed and cells were washed with PBS. Cells were then lysed, and cell lysates were incubated with luciferin, followed by luminescence measurement. Luciferase activity was calculated after normalization to the Renilla luciferase activity.

Statistical analysis. Results are presented as the mean \pm standard deviation. All statistical analyses were performed using SPSS 16.0 software (SPSS Inc., Chicago, IL, USA). Comparisons between groups were investigated by two-tailed Student's t-test. Tukey's test was used as a post hoc test following analysis of variance. Differences were considered as statistically significant when the P-value was $<0.05$.

\section{Results}

miR-9 expression is reduced in PC cells and tissues. To identify whether miR-9 is an essential regulator in PC progression and development, miR-9 expression was examined in a PC mouse model, human PC tissues and six different PC cell lines, including the brain metastatic PC cell line DU145, the lymph node metastatic cell line LNCaP, the primary PC cell line 22Rv1, and the bone metastatic PC cell lines PC-3, C4-2B and VCaP. Initially, miR-9 expression was examined in normal prostate cells (RWPE-1) $(35,36)$ and the six PC cell lines. RT-qPCR analysis revealed that miR-9 expression was significantly reduced in the six PC cell lines compared with that in the normal cell line (Fig. 1A). In addition, the expression levels of miR-9 were evaluated in 31 human PC prostatic tissues and 16 adjacent normal tissues. The results revealed that miR-9 expression was significantly lower in human prostatic tissues in comparison with that in normal tissues (Fig. 1B). Furthermore, the expression of miR-9 was measured in normal mouse prostatic tissues and prostatic tumor collected from a PC mouse model. It was observed that miR-9 expression was markedly reduced in prostate tumors of the mouse model, as compared with that in the normal group (Fig. 1C). Taken together, these data demonstrated that PC cells and tissues exhibited a marked decrease in miR-9 expression, compared with that observed in normal cells or tissues, respectively.

Effect of miR-9 on PC cell viability. To assess the role of miR-9 on the growth and viability of PC cells, miR-9-mimic or miR-NC were transfected into DU145, LNCaP, 22Rv1, PC-3, C4-2B and VCaP cells. The expression pattern of miR-9 was confirmed to be upregulated in these six PC cell lines following transfection with miR-9-mimic, as compared with cells transfected with miR-NC and untransfected cells, by RT-qPCR assay (Fig. 2A). A CCK-8 assay was also performed to assess the proliferation of the six cell lines. Compared with the miR-NC group, transfection with miR-9-mimic at a 
A
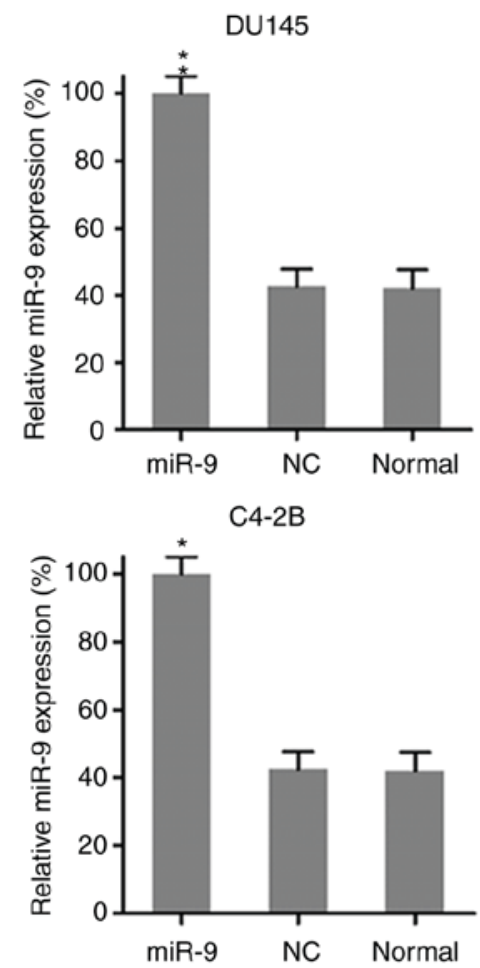

B

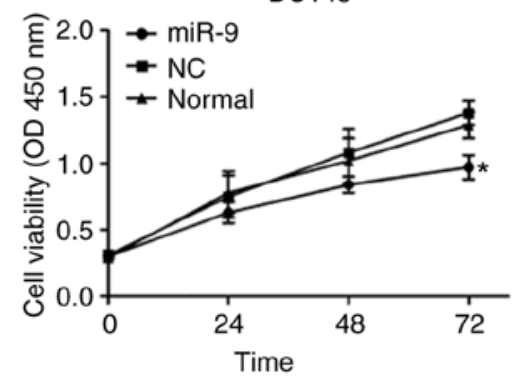

C4-2B

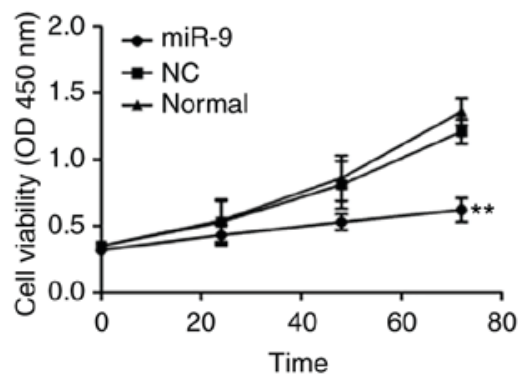

C

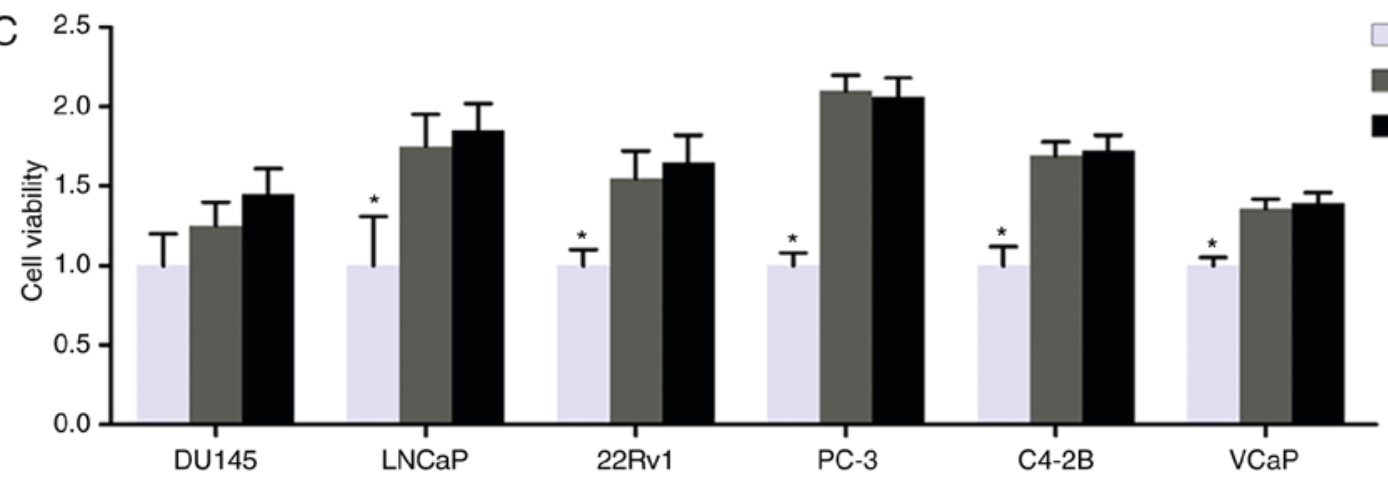

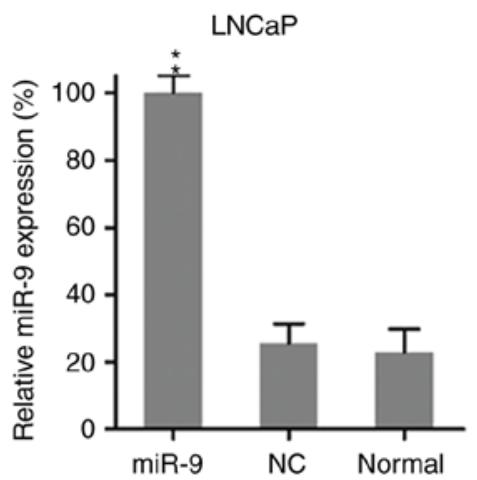
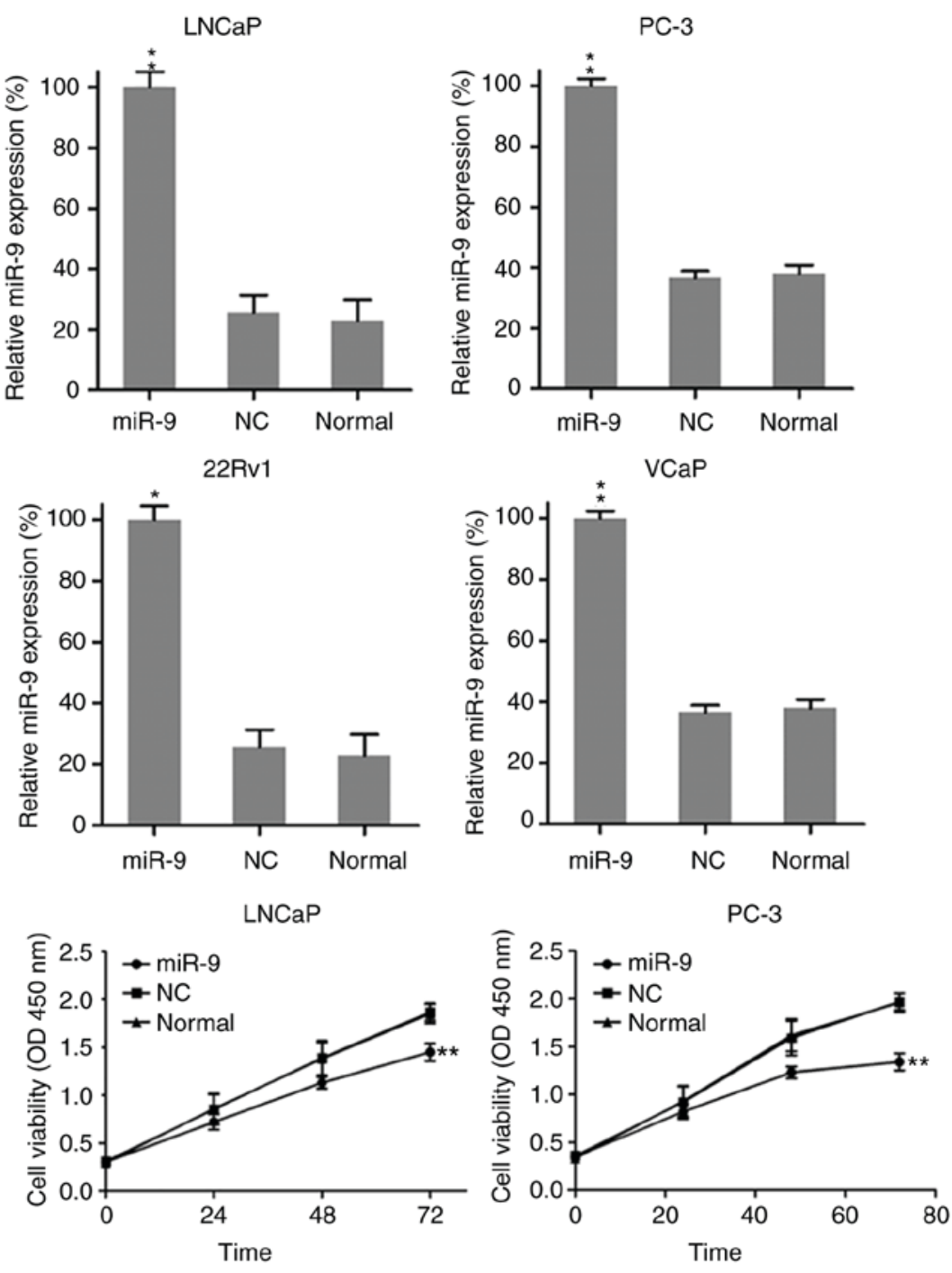

22Rv1
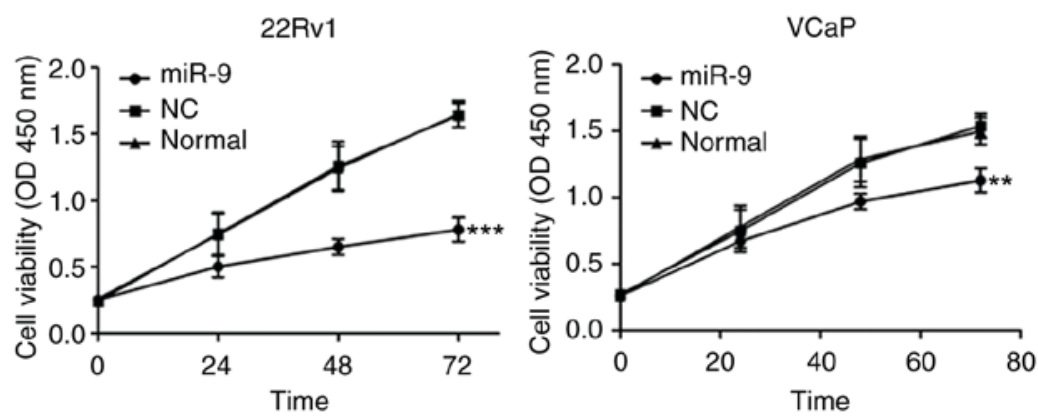

$\square$ miR-9

$\square \mathrm{NC}$

Normal 
A

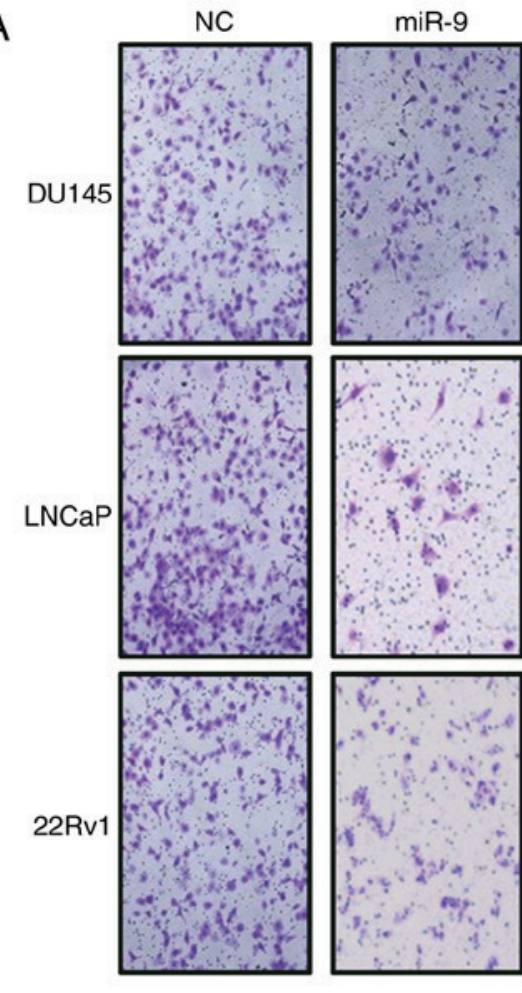

B
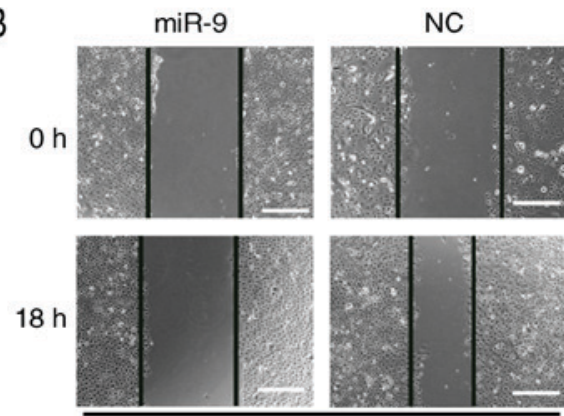

DU145
NC
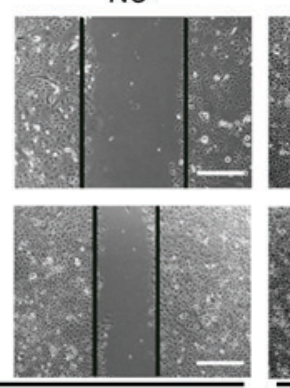
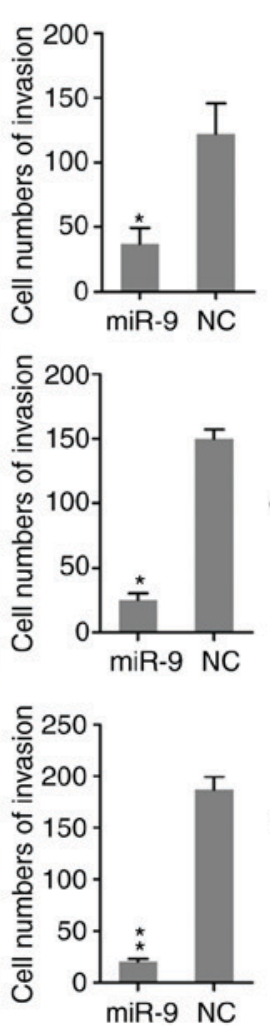

PC-3
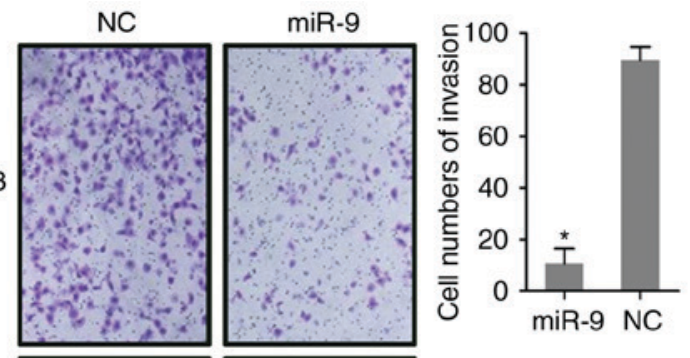

C4-2B
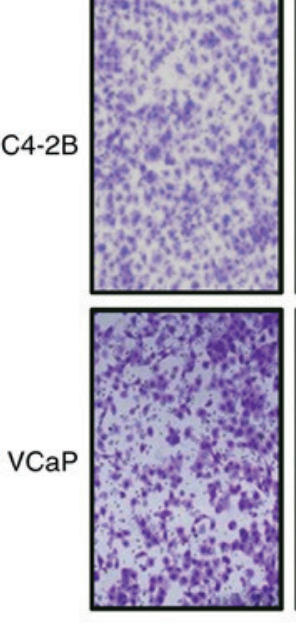

miR-9
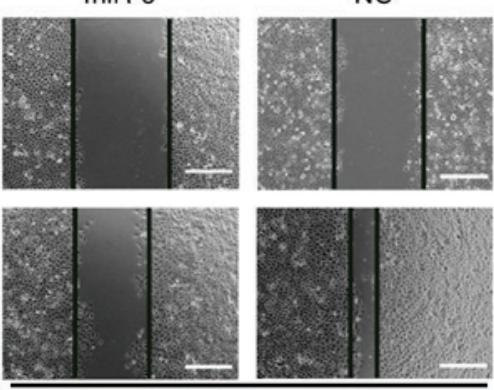

22Rv1
NC
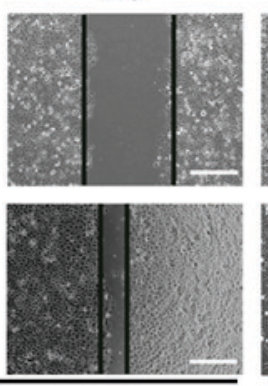
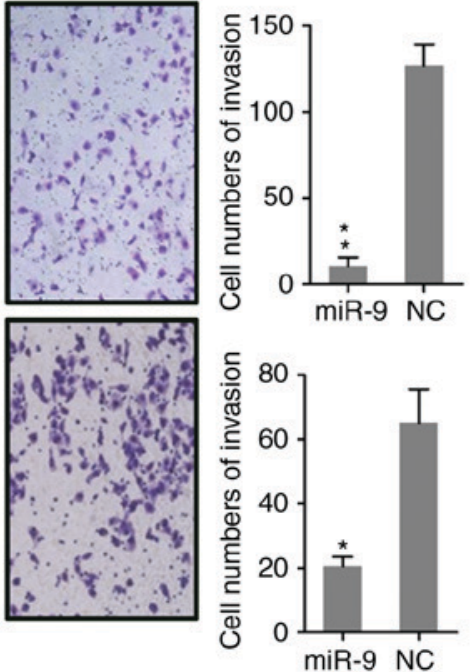

Figure 3. miR-9 overexpression suppressed PC cell migration and invasion. Subsequent to miR-9 mimic transfection, the invasion and migration of various PC cells were measured by (A) Transwell assay and (B) wound-healing assay. Representative data from three independent experiments are presented as the mean \pm standard deviation. ${ }^{*} \mathrm{P}<0.05$ and ${ }^{* *} \mathrm{P}<0.01$, vs. $\mathrm{NC}$ group. miR, microRNA; PC, prostate cancer; NC, negative control.

concentration of $100 \mathrm{nM}$ resulted in a decreased cell growth rate in the six PC cell lines at $0,24,48$ and $72 \mathrm{~h}$ after transfection (Fig. 2B). Furthermore, BrdU immunofluorescence assay was performed to measure the cell viability at $48 \mathrm{~h}$ after transfection with miR-9-mimic. The BrdU staining results revealed that, compared with miR-NC and untransfected groups, miR-9-mimic transfection inhibited viability in DU145, LNCaP, 22Rv1, PC-3, C4-2B and VCaP cells by approximately $30,50,40,50,40$ and $30 \%$, respectively; however, the change in DU145 cells was not statistically significant (Fig. 2C). Overall, these results revealed that miR-9 overexpression displayed an inhibitory effect on cell viability in a time-dependent manner in these six PC cell lines.

miR-9 inhibits PC cell migration and invasion. Research has demonstrated that the invasion and migration of PC cells is major cause for mortality during PC development and metastasis into the bone. To determine whether miR-9 expression impacted the invasion and migration of PC cells, wound-healing and Transwell migration were conducted following the transfection of DU145, LNCaP, 22Rv1, PC-3, C4-2B and VCaP cells with miR-9 and miR-NC mimics. The Transwell assay demonstrated that ectopic miR-9 expression had a significant inhibitory effect on invasion of these cells (Fig. 3A), which was consistent with the migration data obtained from the wound-healing assay (Fig. 3B). The wound-healing assay was also performed to detect the migratory capacity of DU145, 22Rv1, and LNCaP cells, and the results revealed that miR-9 overexpression caused marked suppression of these three PC cells migration, particularly in 22Rv1 cells (Fig. 3B). The results suggested that miR-9 overexpression suppressed the migratory and invasive properties of PC cells in vitro.

Effect of miR-9 on EMT. Epithelial-mesenchymal transition (EMT) serves an essential role in tumor invasion and migration. 


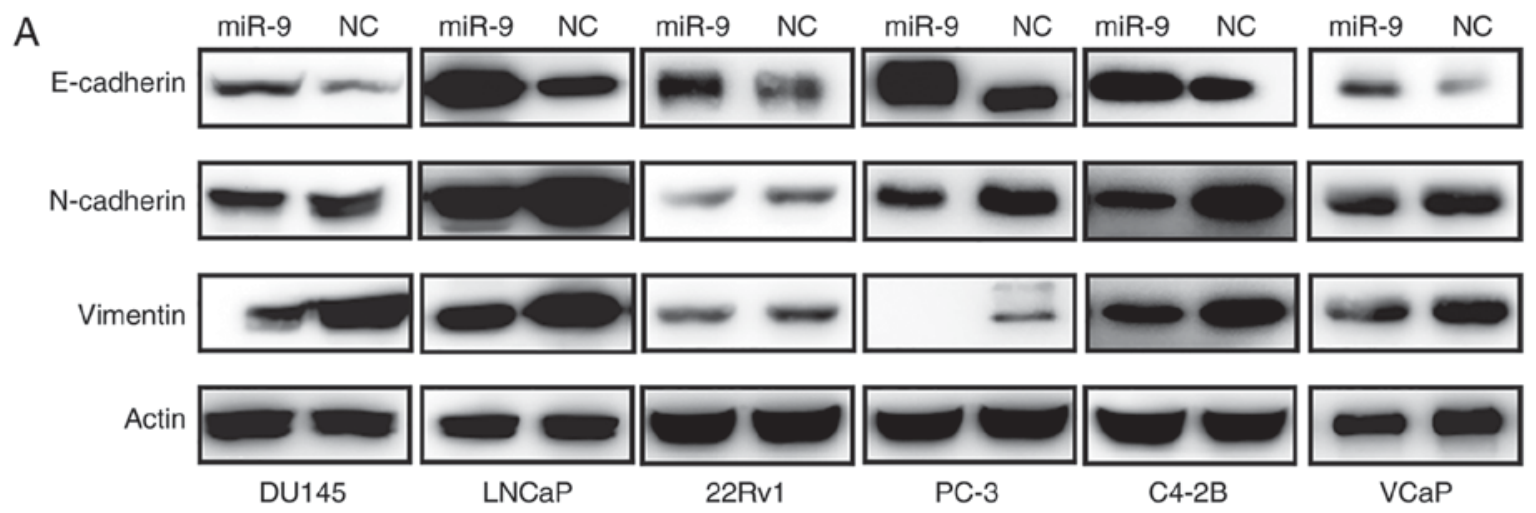

B

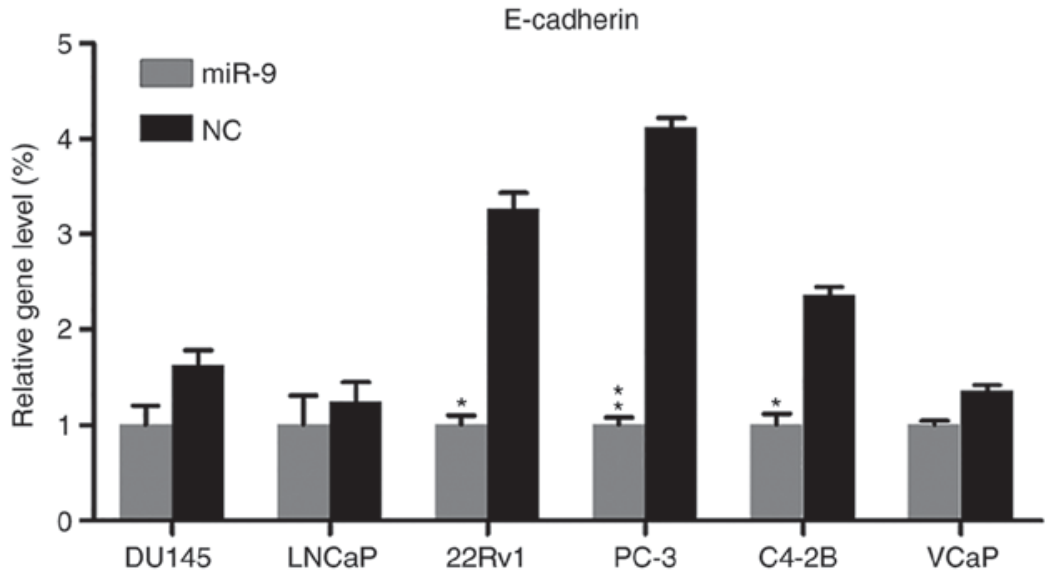

C

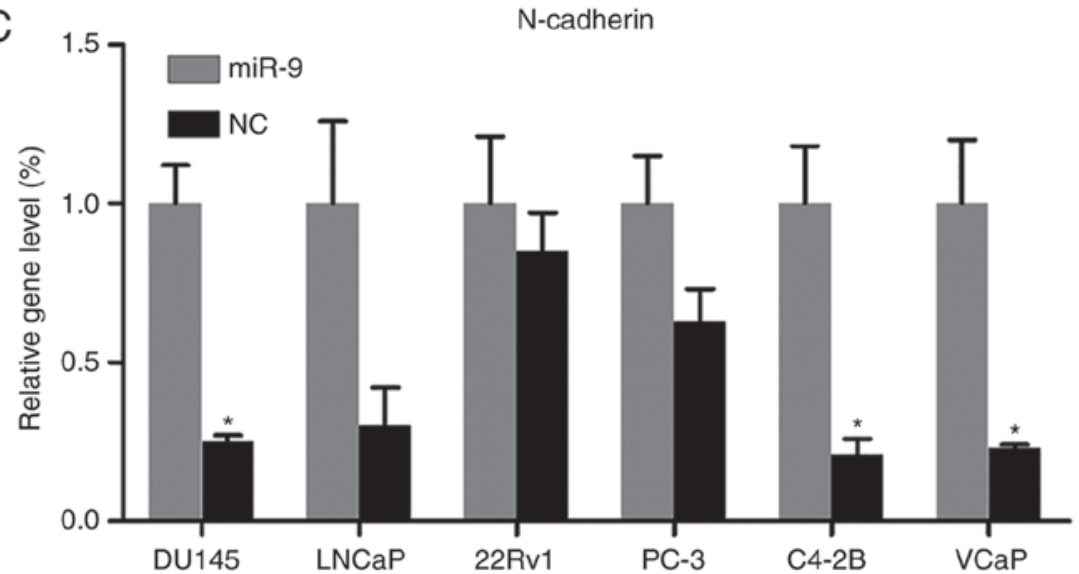

$\mathrm{D}$

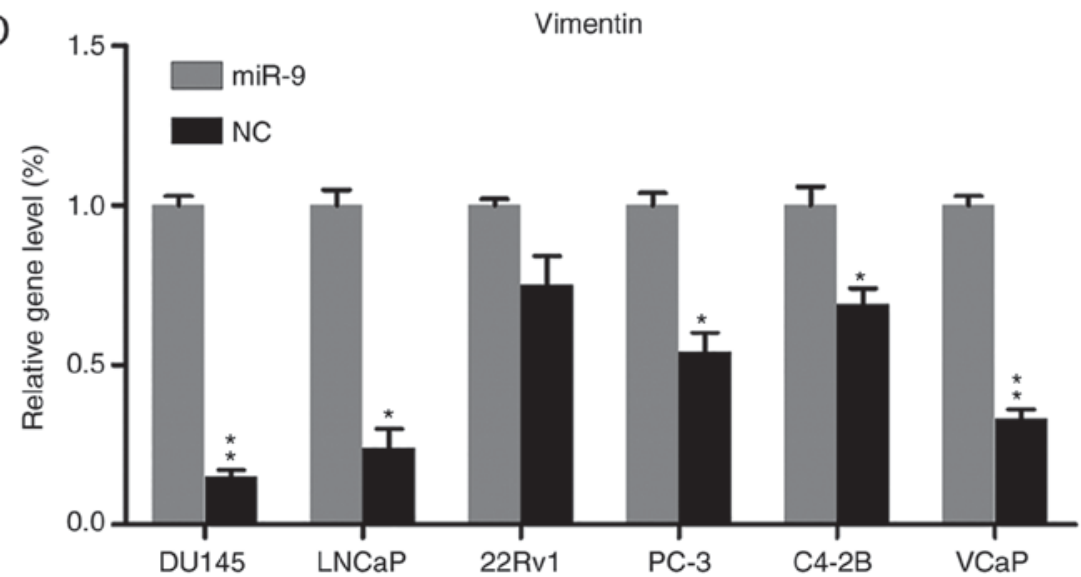

Figure 4. E-cadherin, N-cadherin and Vimentin expression correlates with miR-9 transfection. (A) Western blot analysis of E-cadherin, N-cadherin and Vimentin protein levels in PC cells transfected with miR-9 mimic or miR-NC. (B) E-cadherin, (C) N-cadherin and (D) Vimentin mRNA levels were examined by quantitative polymerase chain reaction in PC cell lines. Representative data from three independent experiments are presented as the mean \pm standard deviation. ${ }^{*} \mathrm{P}<0.05$ and ${ }^{* *} \mathrm{P}<0.01$, vs. NC group. miR, microRNA; PC, prostate cancer; NC, negative control. 


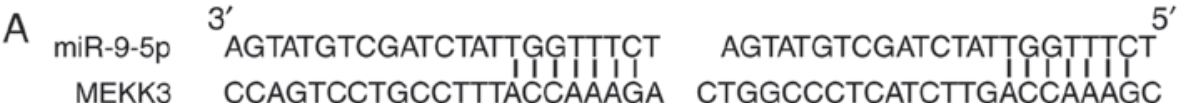
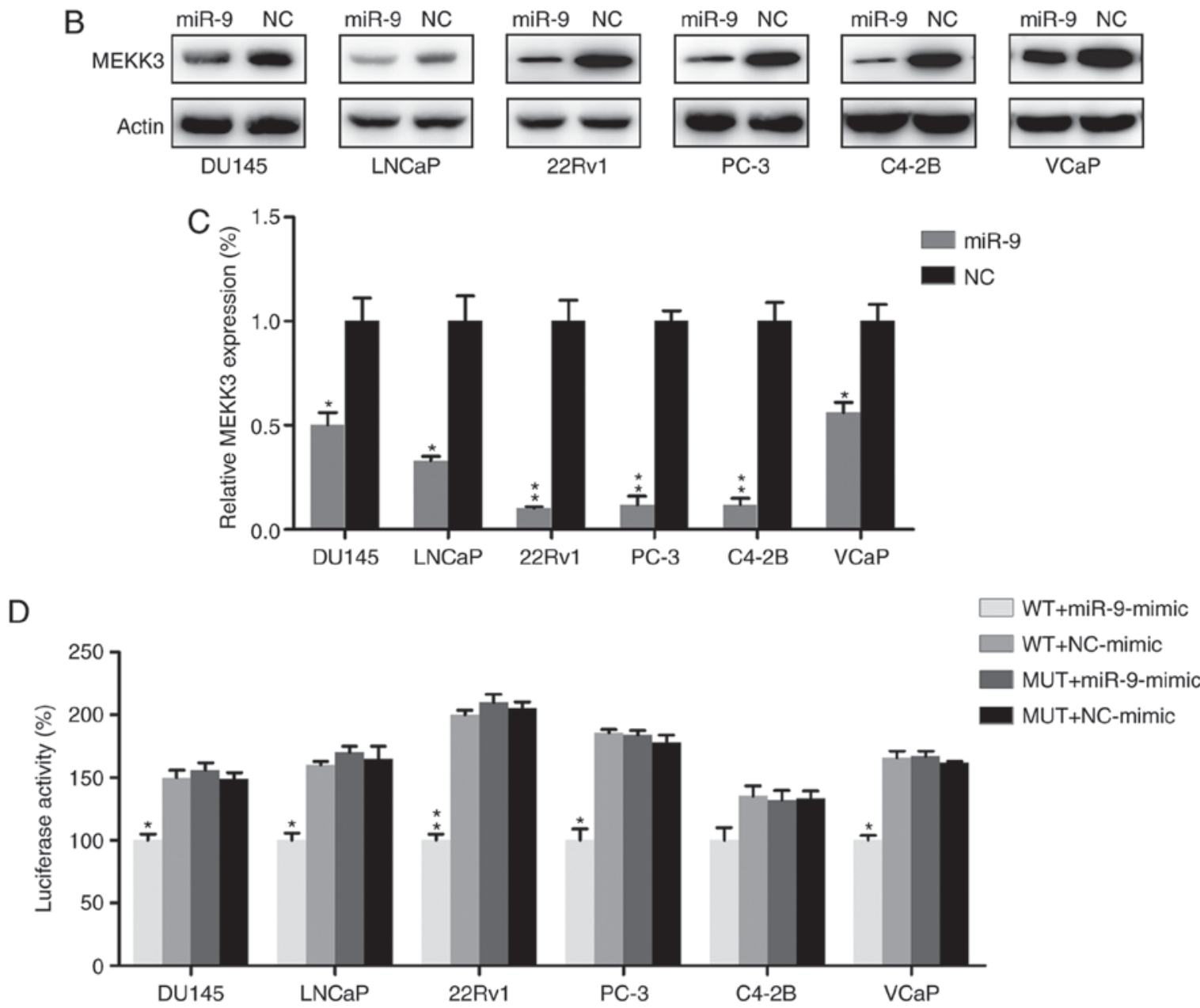

Figure 5. MEKK3 is a direct target of miR-9. (A) Graphical representation of the conserved miR-9 binding motif in the 3'-UTR of MEKK3. The complementary sequences to the seed regions of miR-9 and corresponding sequence of 3'-UTR of MEKK3 were displayed. (B) Western blot analysis and (C) reverse transcription-quantitative polymerase chain reaction were performed to detect the MEKK3 protein and mRNA expression levels after PC cells were transfected with miR-9 mimic and NC mimic. (D) Luciferase activity of the luciferase reporter constructs containing either the WT or MUT 3'-UTR of human MEKK3 following miR-9 mimic transfection. The luciferase activity was normalized to the activity of $\beta$-galactosidase. miR-9 overexpression markedly decreased the relative luciferase activity in the WT 3'-UTR, but not in the MUT 3'-UTR of MEKK3. Data represent the mean \pm standard deviation. "P<0.05 and ${ }^{* *} \mathrm{P}<0.01$, vs. NC group. miR, microRNA; PC, prostate cancer; NC, negative control; 3'-UTR, 3'-untranslated region; MEKK3, mitogen-activated protein kinase kinase kinase 3; WT, wild-type; MUT, mutant.

Western blotting and RT-qPCR were performed to reveal the effect of miR-9 on EMT, through examining the protein and gene expression levels of epithelial marker E-cadherin, mesenchymal marker $\mathrm{N}$-cadherin and Vimentin. E-cadherin protein expression in each PC cell line of the miR-9 mimic-transfected group was markedly upregulated, compared with that in the NC group. By contrast, N-cadherin and Vimentin expression levels were notably decreased by miR-9 overexpression when compared with those in the NC group (Fig. 4A). In addition, E-cadherin, $\mathrm{N}$-cadherin and Vimentin mRNA expression levels in the miR-9 mimic-transfected groups were significantly changed, compared with those in the $\mathrm{NC}$ group, in the majority of cell lines $(\mathrm{P}<0.05)$. More specifically, E-cadherin mRNA was significantly increased, whereas $\mathrm{N}$-cadherin and Vimentin mRNA levels were markedly reduced in the miR-9 groups (Fig. 4B-D).
$M E K K 3$ is a target of $m i R-9$. MEKK3, which has been well-documented as a mediator of development and migration of other cancers (37-39), was identified as a functional candidate target for miR-9 by bioinformatics analysis (Fig. 5A). MEKK3 expression was thus examined in PC cells transfected with miR-9 mimic or miR-NC mimic by western blot analysis and RT-qPCR. MEKK3 expression was markedly suppressed in the miR-9 mimic-transfected group at the protein and mRNA levels (Fig. 5B and C). A dual-luciferase reporter assay, which is widely applied to confirm the binding of miRs to the promoter region of genes (40-42), was also performed in PC cell lines to determine if there was a direct interaction between MEKK3 and miR-9. The data demonstrated that miR-9 mimic transfection decreased luciferase activity, which was fused with the MEKK3 3'-UTR, as compared with in the control group (Fig. 5D). 

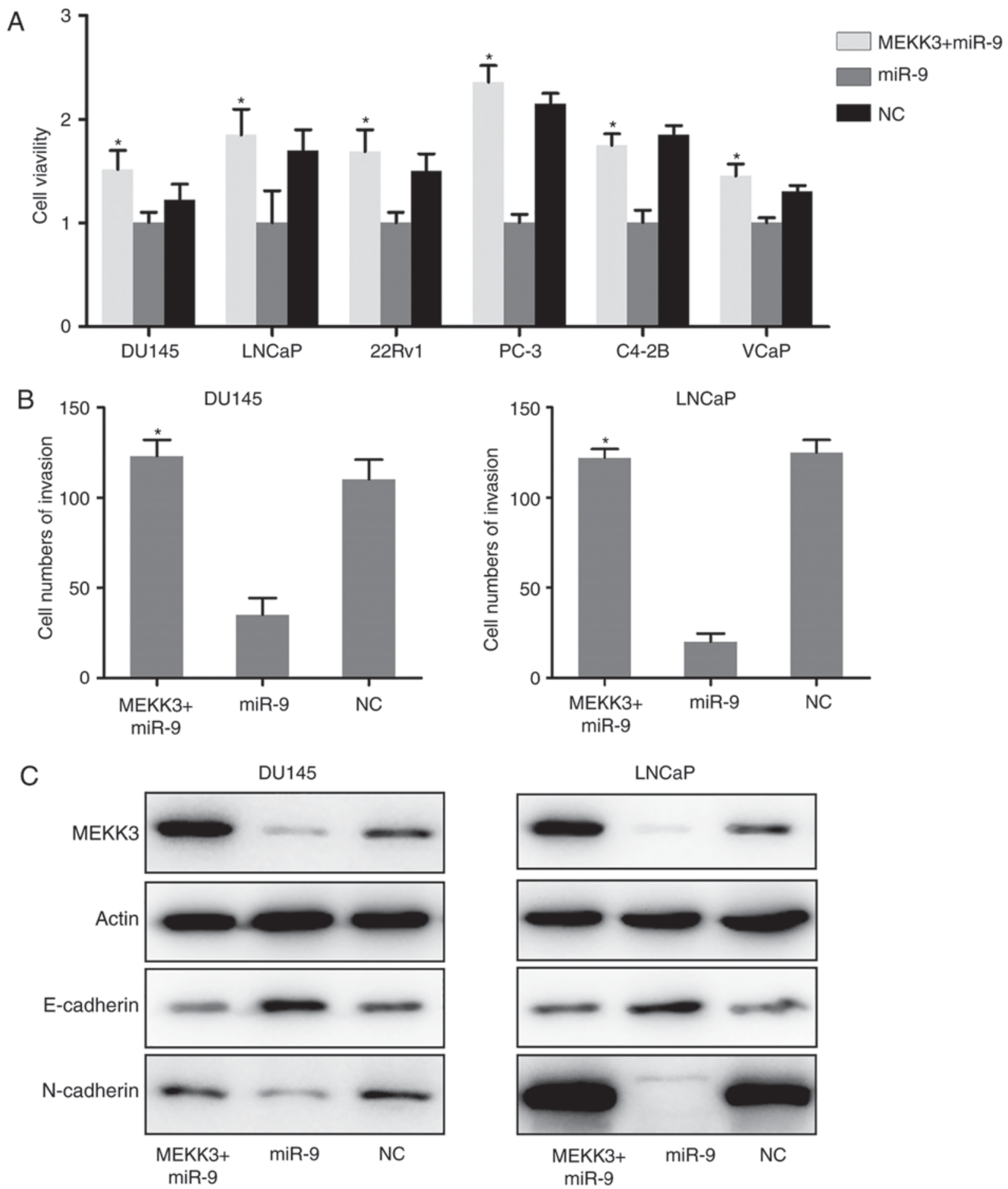

Figure 6. MEKK3 overexpression restored the inhibitory effect of miR-9 on the PC cell properties. (A) Viability of PC cells overexpressing MEKK3 + miR-9 or miR-9 alone was measured by Cell Counting Kit-8 assay at 0, 24, 48, and $72 \mathrm{~h}$ post transfection. (B) After miR-9 mimic and MEKK3-expressing plasmid transfection, the invasion ability of DU145 and LNCaP cells was measured by Transwell assay. (C) Western blot analysis was performed to assess the MEKK3, E-cadherin and N-cadherin expression levels, which were regulated by miR-9 mimic and MEKK3 plasmid co-transfection in DU145 and LNCaP cells. Data represent the mean \pm standard deviation. "P $<0.05$ vs. miR-9 group. miR, microRNA; PC, prostate cancer; NC, negative control; MEKK3, mitogen-activated protein kinase kinase kinase 3.

Overexpression of MEKK3 protein suppresses the inhibitory effect of miR-9 on PC cell viability and migration. To further determine whether the inhibitory effect of miR-9 on PC development was exerted through targeting MEKK3, the expression of MEKK3 was we restored in six PC cell lines (DU145, LNCaP, 22Rv1, PC-3, C4-2B and VCaP cells) expressing miR-9. By performing a BrdU immunofluorescence assay, it was identified that increased expression of MEKK3 inhibited the miR-9-mediated viability decrease of DU145, LNCaP, 22Rv1, PC-3, C4-2B and VCaP cells (Fig. 6A). Transwell migration assays for DU145 and LNCaP cells, which have showed best invasive capacity in above mentioned experiments, were performed to further assess the effect of MEKK3 overexpression on these PC cells that were overexpressing 
miR-9. As expected, the MEKK3 + miR-9-overexpressing cells displayed enhanced invasive capacity, compared with in the group transfected with miR-9 mimic alone (Fig. 6B). MEKK3 overexpression also inhibited the miR-9-induced E-cadherin upregulation and $\mathrm{N}$-cadherin downregulation (Fig. 6C). Taken together, the data indicated that increased MEKK3 expression reduced the miR-induced inhibition of PC cell growth and invasion. The data also strongly suggested that the inhibitory effect observed in PC cells by miR-9 overexpression was exerted through cross-talk between miR-9 and MEKK3.

miR-9 inhibits prostate tumor growth in vivo. To further demonstrate the effect of miR-9 on PC development in vivo, a mouse model was established through intratibial injection. The mice were sacrificed, and tumors were excised and weighed at 30 days after injection. As presented in Fig. 7A, upregulation of miR-9 inhibited the xenograft prostate tumor development ability in vivo. In addition, mice injected with PC cells that were transfected with miR-9 mimics exhibited a marked reduction in tumor volumes compared with those inoculated with control PC cells (Fig. 7B). Furthermore, overexpression of miR-9 greatly reduced the weight of tumors (Fig. 7C). These observations indicated that the upregulation of miR-9 repressed prostate tumor formation.

\section{Discussion}

Tumor development is a complex synergistic process, involving the activation of oncogenic and suppression of tumor suppressor signaling networks, which may be associated with epigenetic alterations. Although PC has been extensively investigated in previous studies, the underlying mechanisms of PC remain poorly understood due to its complexity. In the present study, a specific miRNA was identified, namely miR-9, which was downregulated in six different PC cell lines (DU145, LNCaP, 22Rv1, PC-3, C4-2B, and VCaP). In addition, it was observed that overexpression of miR-9 in these cell lines inhibited cell viability and migration. In vivo experiments demonstrated that the inoculation of PC-3 cells expressing miR-9 into an immune-deficient mouse model resulted in a robust inhibitory effect on prostate tumor growth. The ability of miR-9 to inhibit the expression of MEKK3, a key diagnostic and therapeutic target of PC, was also identified. Further investigation demonstrated that miR-9 directly bound to the 3'-UTR of MEKK3 and abrogated its expression. Restoration of MEKK3 expression prevented the inhibitory effects of miR-9 in PC cells. The findings of the present study strongly suggested that miR-9 suppressed PC development via the regulation of cell viability through MEKK3 regulation, and provided evidence for the use of this miRNA as a potential target in PC therapy.

Accumulating studies have focused on the effects of miRNAs in PC therapy, due to their stability and relatively high uptake by the prostate (43). The identified inhibitory effect of miR-9 on PC was not unpredictable, since its role as an oncogene or tumor suppressor, depending on the cancer type, has been previously established. Several studies have demonstrated that miR-9 is upregulated in breast cancer, brain cancer, and melanoma $(17,44,45)$. By contrast, a number of other studies have indicated that miR-9 is downregulated in certain types of cancer, including cervical adenocarcinoma, and hepatocellular, ovarian
A
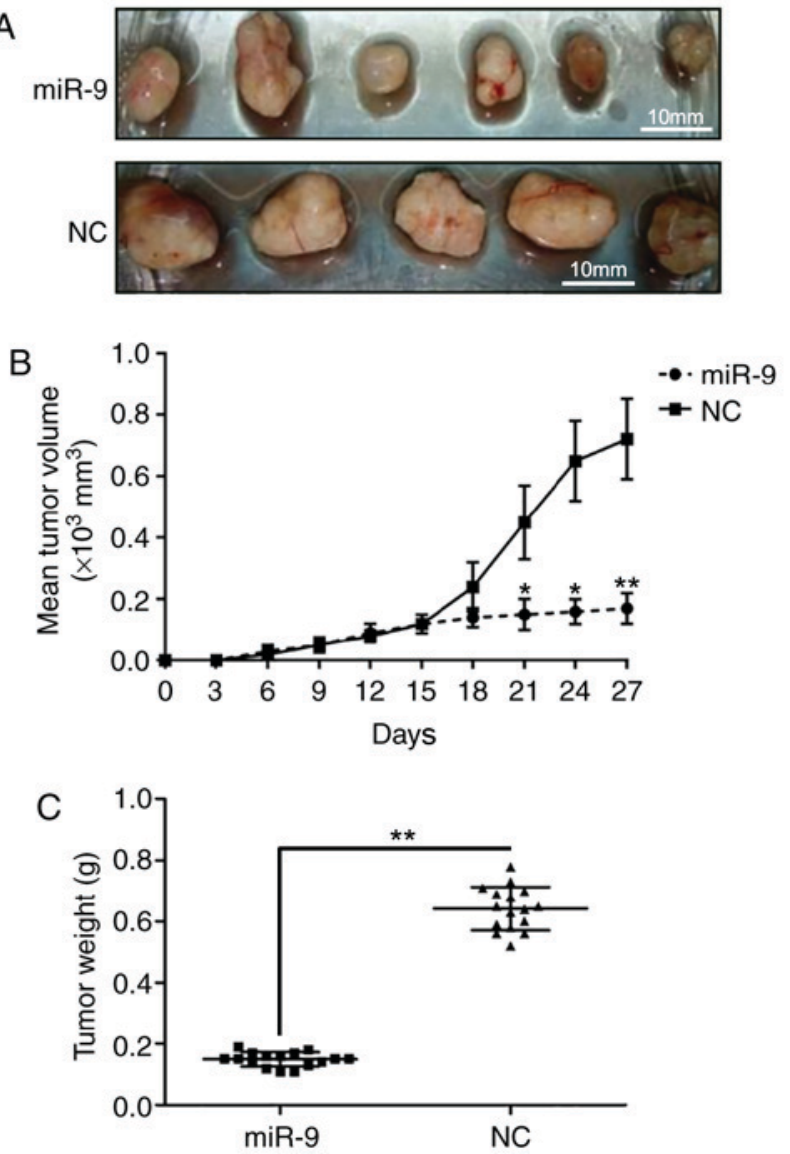

Figure 7. miR-9 suppresses xenograft tumor formation. PC-3 cells with or without overexpression of miR-9 were injected subcutaneously into mice ( $n=6$ per group). (A) Representative photographs of xenograft tumors obtained from mice at day 30 post inoculation were displayed. Mice were sacrificed and tumor tissues were weighted at day 30 post inoculation. (B) Tumor growth curve is displayed. (C) Tumor weight, measured at day 30 post injection. Data are presented as the mean \pm standard deviation. ${ }^{*} \mathrm{P}<0.05$ and ${ }^{* *} \mathrm{P}<0.01$, vs. NC group. miR, microRNA; NC, negative control.

and gastric carcinoma (20,46-49), suggesting a bidirectional role of miR-9 in cancer. Accordingly, miR-9 may have different gene targets depending on the tumor type. In the current study, miR-9 expression in PC cell lines and tumor tissues obtained from 31 PC patients was significantly downregulated compared with that in normal cells and tissues. However, restoration of miR-9 expression in PC cells inhibited the cell viability in vitro and tumor development in vitro. Furthermore, the data demonstrated that miR-9 expression was inversely associated with MEKK3 expression in PC cell lines.

MEKK3, a member of the MEKK family, is ubiquitously expressed in various human tissues; however, increased MEKK3 expression in cancer indicates a high risk of tumor progression and is correlated with poor prognosis. MEKK is an upstream regulator of the MAPK cascade and activates multiple MAPKs, including ERK1/2, p38, JNK, ERK5 and nuclear factor (NF)- $\mathrm{KB}(50)$. The role of MAPKs in tumorigenesis has been extensively investigated over the last decade, particularly in the cases of ERK1/2 and NF- $\mathrm{KB}$ (51). Recently, the focus of research has shifted to the potential role of MEKKs in tumor development and progression. For instance, MEKK3 has been reported to contribute to the development of cervical (37), breast (24) and esophageal cancer (32). It also 
has the ability to induce tumor cell migration and invasion via MAPK pathway activation. In the present study, MEKK3 was identified to be a direct target of miR-9. Previously, it has been proven that positive results in dual-luciferase reporter assay, combined with the identification of the miR-downregulated target protein, are sufficient to verify the interaction between miR and the gene of the target protein (40-42). This provides evidence for the function of miR-9 in the regulation of PC cell proliferation, migration, invasion and EMT, at least partially through targeting the 3'-UTR of MEKK3.

EMT is the transformation process of epithelial cells into mesenchymal cells. It has also been demonstrated to be involved in tumor development and progression, particularly in tumor metastasis (52). In the present study, MEKK3 overexpression markedly reduced the inhibitory effect of miR-9 transfection on PC viability, invasion and EMT marker expression. The present data demonstrated that miR-9 may suppress the neoplastic capacity of PC cells.

In conclusion, the data presented in the current study suggested that miR-9 exerted a multifunctional anti-tumor effect against the major malignant properties of PC cell lines. In addition, it was revealed that miR-9 reduced tumor development in a PC mouse model. These effects were demonstrated to be, at least partially, mediated by MEKK3 regulation. Nevertheless, it cannot be excluded that miR-9 may target other factors and thus contribute to PC pathogenesis. Therefore, a modified HITS-CLIP method combined with the miR-TRAP technique, which was introduced by Baigude et al (53), will be applied in our future investigations to screen and identify the targets of miR-9 in PC cell lines and the prostate tissue of a PC mouse model. This method may provide a more precise and comprehensive interpretation for the role of miR-9 in PC development.

\section{Acknowledgements}

Not applicable.

\section{Funding}

This study was supported by a grant from the Shandong Science and Technology Research Program (no. 2014GSF121026).

\section{Availability of data and materials}

The analyzed data sets generated during the study are available from the corresponding author on reasonable request.

\section{Authors' contributions}

XJ performed the CCK- 8 assay. ZS performed all other assays. LG analyzed the data and wrote the manuscript. GY conceived the study and designed the experiments. All authors read and approved the final manuscript.

\section{Ethics approval and consent to participate}

The human specimen experiments were approved by the Ethical Committees of Qilu Hospital of Shandong University (Jinan, China), and written informed consent for sample use was obtained from patients and clinicians. Ethical approval for the animal experiments was provided by the Institutional Animal Care and Use Committee of Shandong University Cancer Center (approval no. L102012016110D).

\section{Patient consent for publication}

Written informed consent for sample use and publication in this research was obtained from both patients and clinicians.

\section{Competing interests}

The authors declare that they have no competing interests.

\section{References}

1. Siegel RL, Miller KD and Jemal A: Cancer statistics, 2015. CA Cancer J Clin 65: 5-29, 2015.

2. Gomella LG, Singh J, Lallas C and Trabulsi EJ: Hormone therapy in the management of prostate cancer: Evidence-based approaches. Ther Adv Urol 2: 171-181, 2010.

3. Torre LA, Bray F, Siegel RL, Ferlay J, Lortet-Tieulent J and Jemal A: Global cancer statistics, 2012. CA Cancer J Clin 65: 87-108, 2015.

4. Fidler IJ: The pathogenesis of cancer metastasis: The 'seed and soil' hypothesis revisited. Nat Rev Cancer 3: 453-458, 2003.

5. Weigelt B, Peterse JL and van't Veer LJ: Breast cancer metastasis: Markers and models. Nat Rev Cancer 5: 591-602, 2005.

6. Gupta GP and Massague J: Cancer metastasis: Building a framework. Cell 127: 679-695, 2006.

7. Lee RC, Feinbaum RL and Ambros V: The C. elegans heterochronic gene lin-4 encodes small RNAs with antisense complementarity to lin-14. Cell 75: 843-854, 1993.

8. Kozomara A and Griffiths-Jones S: miRBase: Integrating microRNA annotation and deep-sequencing data. Nucleic Acids Res 39: D152-D157, 2011.

9. Hummel R, Hussey DJ and Haier J: MicroRNAs: Predictors and modifiers of chemo- and radiotherapy in different tumour types. Eur J Cancer 46: 298-311, 2010.

10. Lim LP, Lau NC, Garrett-Engele P, Grimson A, Schelter JM, Castle J, Bartel DP, Linsley PS and Johnson JM: Microarray analysis shows that some microRNAs downregulate large numbers of target mRNAs. Nature 433: 769-773, 2005.

11. Kim S, Lee UJ, Kim MN, Lee EJ, Kim JY, Lee MY, Choung S, Kim YJ and Choi YC: MicroRNA miR-199a* regulates the MET proto-oncogene and the downstream extracellular signal-regulated kinase 2 (ERK2). J Biol Chem 283: 18158-18166, 2008.

12. Yuva-Aydemir Y, Simkin A, Gascon E and Gao FB: MicroRNA-9: functional evolution of a conserved small regulatory RNA. RNA Biol 8: 557-564, 2011.

13. Shibata M, Kurokawa D, Nakao H, Ohmura T and Aizawa S: MicroRNA-9 modulates cajal-retzius cell differentiation by suppressing foxg1 expression in mouse medial pallium. J Neurosci 28: 10415-10421, 2008.

14. Leucht C, Stigloher C, Wizenmann A, Klafke R, Folchert A and Bally-Cuif L: MicroRNA-9 directs late organizer activity of the midbrain-hindbrain boundary. Nat Neurosci 11: 641-648, 2008.

15. Delaloy C, Liu L, Lee JA, Su H, Shen F, Yang GY, Young WL, Ivey KN and Gao FB: MicroRNA-9 coordinates proliferation and migration of human embryonic stem cell-derived neural progenitors. Cell Stem Cell 6: 323-335, 2010.

16. Pietrzykowski AZ, Friesen RM, Martin GE, Puig SI, Nowak CL, Wynne PM, Siegelmann HT and Treistman SN: Posttranscriptional regulation of BK channel splice variant stability by miR-9 underlies neuroadaptation to alcohol. Neuron 59: 274-287, 2008.

17. Ma L, Young J, Prabhala H, Pan E, Mestdagh P, Muth D, Teruya-Feldstein J, Reinhardt F, Onder TT, Valastyan S, et al: miR-9, a MYC/MYCN-activated microRNA, regulates E-cadherin and cancer metastasis. Nat Cell Biol 12: 247-256, 2010.

18. Iorio MV, Ferracin M, Liu CG, Veronese A, Spizzo R, Sabbioni S, Magri E, Pedriali M, Fabbri M, Campiglio M, et al: MicroRNA gene expression deregulation in human breast cancer. Cancer Res 65: 7065-7070, 2005.

19. Lehmann U,Hasemeier B,Christgen M, Müller M, Römermann D, Länger $\mathrm{F}$ and Kreipe $\mathrm{H}$ : Epigenetic inactivation of microRNA gene hsa-mir-9-1 in human breast cancer. J Pathol 214: 17-24, 2008 . 
20. Laios A, O'Toole S, Flavin R, Martin C, Kelly L, Ring M, Finn SP, Barrett C, Loda M, Gleeson N, et al: Potential role of miR-9 and miR-223 in recurrent ovarian cancer. Mol Cancer 7: 35, 2008.

21. Nie K, Gomez M, Landgraf P, Garcia JF, Liu Y, Tan LH, Chadburn A, Tuschl T, Knowles DM and Tam W: MicroRNA-mediated down-regulation of PRDM1/blimp-1 in hodgkin/reed-sternberg cells: A potential pathogenetic lesion in hodgkin lymphomas. Am J Pathol 173: 242-252, 2008.

22. Hu Q, Shen W, Huang H, Liu J, Zhang J, Huang X, Wu J and Shi Y: Insight into the binding properties of MEKK3 PB1 to MEK5 PB1 from its solution structure. Biochemistry 46: 13478-13489, 2007.

23. Nakamura K, Kimple AJ, Siderovski DP and Johnson GL: PB1 domain interaction of p62/sequestosome 1 and MEKK3 regulates NF-kappaB activation. J Biol Chem 285: 2077-2089, 2010.

24. Fan Y, Ge N, Wang X, Sun W, Mao R, Bu W, Creighton CJ,Zheng P, Vasudevan S, An L, et al: Amplification and over-expression of MAP3K3 gene in human breast cancer promotes formation and survival of breast cancer cells. J Pathol 232: 75-86, 2014.

25. Deng Y, Yang J, McCarty M and Su B: MEKK3 is required for endothelium function but is not essential for tumor growth and angiogenesis. Am J Physiol Cell Physiol 293: C1404-C1411, 2007.

26. Alimirah F, Chen J, Basrawala Z, Xin H and Choubey D: DU-145 and PC-3 human prostate cancer cell lines express androgen receptor: Implications for the androgen receptor functions and regulation. FEBS Lett 580: 2294-2300, 2006.

27. Sramkoski RM, Pretlow TG II, Giaconia JM, Pretlow TP, Schwartz S, Sy MS, Marengo SR, Rhim JS, Zhang D and Jacobberger JW: A new human prostate carcinoma cell line, 22Rv1. In Vitro Cell Dev Biol Anim 35: 403-409, 1999.

28. Korenchuk S, Lehr JE, Mclean L, Lee YG, Whitney S, Vessella R, Lin DL and Pienta KJ: VCaP, a cell-based model system of human prostate cancer. In Vivo 15: 163-168, 2001.

29. Thalmann GN, Anezinis PE, Chang SM, Zhau HE, Kim EE, Hopwood VL, Pathak S, von Eschenbach AC and Chung LW: Androgen-independent cancer progression and bone metastasis in the LNCaP model of human prostate cancer. Cancer Res 54 2577-2581, 1994.

30. Claxton K, Martin S, Soares M, Rice N, Spackman E, Hinde S, Devlin N, Smith PC and Sculpher M: Methods for the estimation of the National Institute for Health and Care Excellence cost-effectiveness threshold. Health Technol Assess 19: 1-503, 2015.

31. Jayandharan GR, Zhong L, Sack BK, Rivers AE, Li M, Li B, Herzog RW and Srivastava A: Optimized adeno-associated virus (AAV)-protein phosphatase-5 helper viruses for efficient liver transduction by single-stranded AAV vectors: Therapeutic expression of factor IX at reduced vector doses. Hum Gene Ther 21: 271-283, 2010.

32. Hasan R, Sharma R, Saraya A, Chattopadhyay TK, DattaGupta S, Walfish PG, Chauhan SS and Ralhan R: Mitogen activated protein kinase kinase kinase 3 (MAP3K3/MEKK3) overexpression is an early event in esophageal tumorigenesis and is a predictor of poor disease prognosis. BMC Cancer 14: 2, 2014.

33. Samanta AK, Huang HJ, Bast RC Jr and Liao WS: Overexpression of MEKK3 confers resistance to apoptosis through activation of NFkappaB. J Biol Chem 279: 7576-7583, 2004

34. Livak KJ and Schmittgen TD: Analysis of relative gene expression data using real-time quantitative PCR and the 2(-Delta Delta C(T)) method. Methods 25: 402-408, 2001

35. Liu Y, Xu X, Xu X, Li S, Liang Z, Hu Z, Wu J, Zhu Y, Jin X, Wang X, et al: MicroRNA-193a-3p inhibits cell proliferation in prostate cancer by targeting cyclin D1. Oncol Lett 14: 5121-5128, 2017.
36. Huang S, Wa Q, Pan J, Peng X, Ren D, Huang Y, Chen X and Tang Y: Downregulation of miR-141-3p promotes bone metastasis via activating NF- $\mathrm{BB}$ signaling in prostate cancer. J Exp Clin Cancer Res 36: 173, 2017.

37. Cao XQ, Lu HS, Zhang L, Chen LL and Gan MF: MEKK3 and survivin expression in cervical cancer: Association with clinicopathological factors and prognosis. Asian Pac J Cancer Prev 15: 5271-5276, 2014

38. Chen Q, Lu HS, Gan MF, Chen LX, He K, Fan GM and Cao XQ Expression and prognostic role of MEKK3 and pERK in patients with renal clear cell carcinoma. Asian Pac J Cancer Prev 16: 2495-2499, 2015.

39. Santoro R, Zanotto M, Carbone C, Piro G, Tortora G and Melisi D: MEKK3 sustains EMT and stemness in pancreatic cancer by regulating YAP and TAZ transcriptional activity. Anticancer Res 38: 1937-1946, 2018.

40. Wa Q, Li L, Lin H, Peng X, Ren D, Huang Y, He P and Huang S: Downregulation of miR19a3p promotes invasion, migration and bone metastasis via activating TGF $\beta$ signaling in prostate cancer. Oncol Rep 39: 81-90, 2018.

41. Yang Y, Ji C, Guo S, Su X, Zhao X, Zhang S, Liu G, Qiu X, Zhang Q, Guo $\mathrm{H}$ and Chen H: The miR-486-5p plays a causative role in prostate cancer through negative regulation of multiple tumor suppressor pathways. Oncotarget 8: 72835-72846, 2017.

42. Yamada Y, Nishikawa R, Kato M, Okato A, Arai T, Kojima S, Yamazaki K, Naya Y, Ichikawa T and Seki N: Regulation of HMGB3 by antitumor miR-205-5p inhibits cancer cell aggressiveness and is involved in prostate cancer pathogenesis. J Hum Genet 63: 195-205, 2018.

43. Kanwal R, Plaga AR, Liu X, Shukla GC and Gupta S: MicroRNAs in prostate cancer: Functional role as biomarkers. Cancer Lett 407: 9-20, 2017.

44. Nass D, Rosenwald S, Meiri E, Gilad S, Tabibian-Keissar H, Schlosberg A, Kuker H, Sion-Vardy N, Tobar A, Kharenko O, et al: MiR-92b and miR-9/9* are specifically expressed in brain primary tumors and can be used to differentiate primary from metastatic brain tumors. Brain Pathol 19: 375-383, 2009.

45. Shiiyama R, Fukushima S, Jinnin M, Yamashita J, Miyashita A, Nakahara S, Kogi A, Aoi J, Masuguchi S, Inoue Y and Ihn H: Sensitive detection of melanoma metastasis using circulating microRNA expression profiles. Melanoma Res 23: 366-372, 2013.

46. Zhang J, Jia J, Zhao L, Li X, Xie Q, Chen X, Wang J and Lu F: Down-regulation of microRNA-9 leads to activation of IL-6/Jak/STAT3 pathway through directly targeting IL-6 in HeLa cell. Mol Carcinog 55: 732-742, 2016

47. Mohammadi-Yeganeh S, Mansouri A and Paryan M: Targeting of miR9/NOTCH1 interaction reduces metastatic behavior in triple-negative breast cancer. Chem Biol Drug Des 86: 1185-1191, 2015.

48. Higashi T, Hayashi $\mathrm{H}$, Ishimoto $\mathrm{T}$, Takeyama $\mathrm{H}$, Kaida $\mathrm{T}$, Arima $\mathrm{K}$, Taki K, Sakamoto K, Kuroki H, Okabe H, et al: miR-9-3p plays a tumour-suppressor role by targeting TAZ (WWTR1) in hepatocellular carcinoma cells. Br J Cancer 113: 252-258, 2015.

49. Luo H, Zhang H, Zhang Z, Zhang X, Ning B, Guo J, Nie N, Liu B and Wu X: Down-regulated miR-9 and miR-433 in human gastric carcinoma. J Exp Clin Cancer Res 28: 82, 2009.

50. Di Y, Li S, Wang L, Zhang Y and Dorf ME: Homeostatic interactions between MEKK3 and TAK1 involved in NF-kappaB signaling. Cell Signal 20: 705-713, 2008.

51. Dhillon AS, Hagan S, Rath O and Kolch W: MAP kinase signalling pathways in cancer. Oncogene 26: 3279-3290, 2007.

52. Guarino M: Epithelial-mesenchymal transition and tumour invasion. Int J Biochem Cell Biol 39: 2153-2160, 2007.

53. Baigude $\mathrm{H}$, Ahsanullah, Li Z, Zhou $\mathrm{Y}$ and Rana TM: miR-TRAP: A benchtop chemical biology strategy to identify microRNA targets. Angew Chem Int Ed Engl 51: 5880-5883, 2012. 